ORIGINAL ARTICLE

\title{
Registered nurses' experiences of their decision-making at an Emergency Medical Dispatch Centre
}

\author{
Bosse Ek and Marianne Svedlund
}

\begin{abstract}
Aims and objectives. To describe registered nurses' experiences at an Emergency Medical Dispatch Centre.

Background. It is important that ambulances are urgently directed to patients who are in need of immediate help and of quick transportation to a hospital. Because resources are limited, Emergency Medical Dispatch centres cannot send ambulances with high priority to all callers. The efficiency of the system is therefore dependent on triage. Nurses worldwide are involved in patient triage, both before the patient's arrival to the hospital and in the subsequent emergency care. Ambulance dispatching is traditionally a duty for operators at Emergency Medical Dispatch centres, and in Sweden this duty has become increasingly performed by registered nurses.

Design. A qualitative design was used for this study.

Methods. Fifteen registered nurses with experience at Emergency Medical Dispatch centres were interviewed. The participants were asked to describe the content of their work and their experiences. They also described the most challenging and difficult situations according to the critical incidence technique. Content analysis was used.

Results. Two themes emerged during the analysis: 'Having a profession with opportunities and obstacles' and 'Meeting serious and difficult situations', with eight sub-themes. The results showed that the decisions to dispatch ambulances were both challenging and difficult. Difficulties included conveying medical advice without seeing the patient, teaching cardio-pulmonary resuscitation via telephone and dealing with intoxicated and aggressive callers. Conflicts with colleagues and ambulance crews as well as fear of making wrong decisions were also mentioned. Conclusions. Work at Emergency Medical Dispatch centres is a demanding but stimulating duty for registered nurses.

Relevance to clinical practice. Great benefits can be achieved using experienced triage nurses, including increased patient safety and better use of medical resources. Improved internal support systems at Emergency Medical Dispatch centres and striving for a blame-free culture are important factors to attract and retain employees.
\end{abstract}

Key words: ambulance, content analysis, decision-making, emergency, priority, triage

Accepted for publication: 14 August 2014

Authors: Bosse Ek, MSc, RN, Licentiate Student, Department of Nursing Sciences, Mid Sweden University, Östersund; Marianne Svedlund, PhD, RN, Associate Professor, Department of Nursing Sciences, Mid Sweden University, Östersund, Sweden
What does this paper contribute to the wider global clinical community?

- To dispatch and prioritise ambulances is a relative new duty for registered nurses (RNs). The present study illustrates this work as both a challenging and developing opportunity for RNs.

- In triage, RNs must use their clinical competence, health care experience and intuition.

- The fear of making mistakes can lead to the overuse of limited resources in emergency care.
Correspondence: Bosse Ek, Licentiate Student, Department of Nursing Sciences, Mid Sweden University, Östersund SE-831 25, Sweden. Telephone: +46 63165651 or +46 703595188 .

E-mail: bosse.ek@miun.se 


\section{Introduction}

It is very important that ambulances are urgently directed to patients who are in need of immediate help and of quick transportation to a hospital. Because resources are limited, the Emergency Medical Dispatch centres (EMDs) cannot send ambulances with high priority to all callers. The efficiency of the system is therefore dependent on appropriate triage. When registered nurses (RNs) were first employed at EMDs in Sweden, Forslund et al. (2006) described that after initial scepticism, operators transitioned to a more positive view of employing RNs, health care professionals who can better address medically complicated patients and prioritise cases than the operators alone.

\section{Background}

Nurses make important clinical decisions every day, and these decisions affect patients' health (Muir 2004). Critical care nurses make decisions approximately every 30 seconds on average (Bucknall 2000). There is always an element of risk-taking when nurses make decisions (Hedberg \& Sätterlund Larsson 2003). Nurse triage systems were implemented in the 1960s in emergency departments (ED) (Chan \& Chau 2005), as nurses were challenged in the ED to make correct triage decisions and to prioritise and rank nonurgent patients (Andersson et al. 2006). Handysides (1996) described that an effective triage nurse needs to have three capacities: to be able to estimate patient status from a short clinical history, to have knowledge of injuries and pathology and to have a developed intuition.

Research in the field of ambulance triage is mostly aimed at investigating the quality of triage. These studies address substantial methodological problems in which a reference standard for correct prioritisation needs to be established (Gardett et al. 2013). Feldman et al. (2006) compared the EMD priority decisions to the triage that the ambulance crew performed after their assessment of the patient. They found that there was weak evidence that the Medical Priority Dispatch System (MPDS) could identify patients in need of high priority. Sporer et al. (2007) evaluated the ability of MPDS to predict the need of advanced prehospital interventions in 22,000 ambulance dispatches. They found that the sensitivity for detecting this need was high but that the specificity was low. In contrast, Hinchey et al. (2007) found that the MPDS had good specificity in identifying patients with low acuity.

Khorram-Manesh et al. (2010) studied ambulance crews that evaluated the urgent needs of patients when they arrived at the scene. Of the dispatches that were given the highest priority by EMD, the ambulance crew considered that only $27 \%$ needed a high priority status. However, Gardett et al. (2013) argued that there are fundamental differences between the emergency dispatcher's decision of priority and the assessment of the ambulance crew at the patient's location. Additionally, the patient's condition can either become better, worse or stay the same during the time waiting for the ambulance.

Every year nearly one million ambulances are dispatched in Sweden (SOS Alarm AB 2013b). Several studies have displayed the difficulties in prioritising ambulance dispatch (Feldman et al. 2006, Hjälte et al. 2007, Machen et al.2007, Khorram-Manesh et al. 2010, Ek et al. 2013, Gardett et al. 2013). Because RNs are increasingly responsible for this prioritisation process, $\mathrm{RNs}^{\prime}$ experiences of decision-making needs to be illuminated. Therefore, our aim was to describe registered nurses' experiences at an EMD.

\section{Methods}

\section{Settings}

The telephone number ' 112 ' is the public emergency phone number for all EU countries. In Sweden, an operator answers the call at an EMD and asks questions to determine if there is an emergency and the resources that are needed (SOS Alarm AB 2013a). A growing number of Sweden's 21 county councils and regions now demand that an RN conduct triage (Swedish National Audit Office 2012). There are 15 EMDs in Sweden and they are all connected to each other to prevent long waiting times. The calls to the EMD can therefore come from any part of the country. At five of the centres, RNs are employed for triage, and the remaining EMD operators can transfer a call to an RN for medical triage (SOS Alarm AB 2013a).

When a call to 112 is transferred to an $\mathrm{RN}$ for triage, the RN will decide if an ambulance should be sent. The patient may also be encouraged to use his or her own transportation or to wait and seek other options for medical examination (e.g., at a health centre). Because resources are limited, ambulances need to be dispatched based on correct indications and priorities. For particular patients, the right decision determines if a patient survives or is able to seek treatment in time to prevent permanent injury. To attain high security and efficiency in the prioritisation process, a criteria-based index called the 'Swedish Index for Medical Priority Dispatch' (2001) was developed. The questionnaire is an index that has been used in Norway. The Norwegian 
version was developed from the MPDS, which is used worldwide (Feldman et al. 2006).

People with medical questions can also choose to call Swedish Health care Direct (SHD) to reach evidence-based health care advice 24 hours a day. The caller is then interviewed by an RN. If indicated, the call can be directed to an $\mathrm{RN}$ at an EMD who can determine if an ambulance needs to be dispatched (Wahlberg et al. 2003, Ernesäter et al. 2012).

\section{Selection and procedure}

The majority of the Swedish EMDs are driven by SOS Alarm AB. All RNs at a centre in the middle of Sweden were asked to participate. Written information about the purpose of the study was distributed to the RNs by the local manager before RNs were contacted. All of the RNs that regularly worked at the centre chose to participate. Additionally, an RN who had left the centre six months earlier and another RN who had been employed at the SHD during a period when the operators had to direct calls to SHD for triage by nurses also participated. A total of fifteen RNs $(n=15)$ were interviewed. Twelve of the participants were women and three were men. They were aged 33-57 years with an average of 43 years. The participants had an average of 14 years of experience as RNs, and they were employed at the EMD for an average of 15 months. The interviews were performed from March to May 2013.

\section{Data collection}

The RNs at the SOS centre were all interviewed in a room at the EMD. The additional two interviews were conducted at the RN's or the author's workplace. The interviews lasted between 19-40 minutes with an average of $26 \mathrm{~min}$ utes and were performed by the first author.

Before each interview information about the study was repeated. The interviews were open-ended (cf. Patton 2002) to allow the RNs to describe their experiences. The initial question was 'What are your experiences of your work as a nurse at EMD?' Clarifying questions were asked, such as 'What do you mean?' and 'Can you give an example?' Additional questions included 'Please tell me more about the process when you received a call?' and 'Can you describe factors that influenced your decision-making?' All participants were also asked to describe one or two challenging or difficult situations they experienced, according to the critical incidence technique reported by Flanagan (1954). Both the initial question and the additional questions were recorded in an interview guide, and the author allowed the interview to be conducted as a conversation.

\section{Analysis}

The interviews were recorded and transcribed verbatim. Qualitative content analysis was performed based on the interview text. In qualitative research, the focus is to describe and highlight variations by identifying similarities and differences in text content and to establish themes (Patton 2002). First, all of the interviews were read several times to understand the sense of the message. Second, the text was divided into meaning units, consisting of one or several sentences that described an aspect of the aim. Third, the meaning units were condensed to shorten text but still preserve the core meaning and were labelled with codes (cf. Graneheim \& Lundman 2004), which were organised to search for themes (Patton 2002). Finally, two themes and eight sub-themes emerged. Table 1 presents examples of the analysis process. This analysis was not linear and involved moving forwards and backwards between the whole and parts of the text in a dialectic approach. The first author performed the analysis in discussion with the co-author until an agreement was reached.

\section{Ethics}

Approval for the study was granted by the local ethical committee at Mid Sweden University (MIUN 2012/1694). Permission was also granted by the chief physician at SOS Alarm AB. The local director at the EMD in the middle of Sweden gave permission to contact the RNs at the centre and provided a space for the interviews. Written information about the purpose of the study was distributed by the local manager to the RNs. The information stated that the participation was voluntary, their confidentiality was ensured and they had the right to withdraw from the study at any time. The two RNs who were not employed at the EMD were given the same information.

\section{Results}

Two themes: 'Having a profession with opportunities and obstacles'; and, 'Meeting serious and difficult situations'; and eight sub-themes emerged during the analysis.

\section{Having a profession with opportunities and obstacles}

This theme included three sub-themes, 'to use own competence,' 'to be satisfied with decision-making' and 'to be reassured about a decision'. 
Table 1 Examples of the analysis process

\begin{tabular}{|c|c|c|c|c|}
\hline Meaning units & Condensed meaning unit & Code & Sub-theme & Theme \\
\hline $\begin{array}{l}\text { That all I have learnt during these } \\
\text { years as a nurse actually is valuable. Yes, } \\
\text { to be able to prioritise and use my } \\
\text { experiences and knowledge and decide } \\
\text { how fast the ambulance must go } \\
\text { there. (No 5) }\end{array}$ & $\begin{array}{l}\text { The skills and knowledge from } \\
\text { the nursing experiences are } \\
\text { valuable and help the nurse } \\
\text { to prioritise appropriately }\end{array}$ & $\begin{array}{l}\text { Own } \\
\text { experiences }\end{array}$ & $\begin{array}{l}\text { To use own } \\
\text { competence }\end{array}$ & $\begin{array}{l}\text { Having a profession with } \\
\text { opportunities and } \\
\text { obstacles }\end{array}$ \\
\hline $\begin{array}{l}\text {... among the worst ones are your own } \\
\text { colleagues who are not used to be } \\
\text { questioned. "I am actually a nurse. } \\
\text { I have already made a triage, so } \\
\text { I don't need to discuss with anyone" }\end{array}$ & $\begin{array}{l}\text { The nurse colleagues are among } \\
\text { the most difficult. They don't } \\
\text { want to have their decisions } \\
\text { questioned }\end{array}$ & Criticised & To be criticised & $\begin{array}{l}\text { Meeting serious and } \\
\text { difficult situations }\end{array}$ \\
\hline
\end{tabular}

\section{To use own competence}

The work at the EMD was described as an opportunity to use the knowledge and skills from earlier nursing experiences. The operators who have worked for a long time are perfect in their work, but I believe I can make things a bit better by catching the nuances (No 5). The RNs were grateful to be able to use their nursing skills. The nurses found it satisfying to focus on one case at a time, and they compared the experience to working at a hospital, where they were responsible for an entire ward. They also found it very comforting to help people in need, and they described how they tried to discover the best possible solutions. They reported that they used their intuition to prioritise situations in which the medical index did not apply. The tacit knowledge which you can't clear describe.... Sometimes it is a little gut feeling that makes it a priority 1 (No 13).

The analysis showed that the Medical Index provided good support in most situations but that it also had imperfections. The Index can guide a decision about dispatching an ambulance, but it can also force the RN to send an ambulance even if there is no need for it. The participants had various opinions about the Index. The medical index doesn't cover everything. There are many question-marks and it is hard directed. It is too detailed in some way, and there are too few nodes (No 2).The RNs stated they needed to balance between strictly following the Index and using common sense and intuition. Afterwards, I can't argue that the Index said that I should. Instead I make my own decisions (No 1).

\section{To be satisfied with decision-making}

The nurses described decision-making as difficult but also positive. The contact that was created with particular callers was considered both deep and trustful. They had strong feelings of relief if a difficult situation resulted in a satisfying end. When you realise there is someone who doesn't breathe, and you get them [the helpers] to start CPR [cardio-pulmonary resuscitation]. Finally, the ambulance crew actually loads a patient. Then you feel very happy for having got them [the helpers] with you. That of course is a great feeling! (No 10). They also stressed the challenges of working at the EMD.

The RNs described the importance of talking directly to the patient if possible. Additionally, they needed to confirm the type of patient and situation because calls were first received by an operator and then forwarded for triage, and this process could lead to misunderstandings. They considered that a good interview with a caller must contain openended questions. Tell me how you feel. ... Tell me how this began (No 1).

\section{To be reassured about a decision}

The RNs often wanted to know more about what happened to particular patients after triage. They wished they had time to follow up on their difficult cases. They also wanted more time to reflect and be reassured after a difficult triage. If they needed support for a decision, they were able to consult with a physician. We have a physician in Stockholm whom we can consult around the clock. That's great. I do so. I find that very comforting when I am in doubt (No 6). 
The RNs also described their wish for more time to follow their 'cases' through the continued chain of care and thereby learn if they made the correct decision. They indicated that the flow of new incoming calls did not allow time for such follow up. One would like to double the number of nurses and to have time for a lot of reflection and also to follow the ambulance during every mission to see what happened (No 10).

\section{Meeting serious and difficult situations}

This theme included the following five sub-themes: 'to give an immediate response,' 'to not obtain reliable information,' 'to give the caller instructions,' 'to get depressing calls' and 'to be criticised'.

\section{To give an immediate response}

Callers who were intoxicated or had psychiatric problems were described as very difficult to adequately assess. A threat of committing suicide is normally very serious and needs an immediate response, but at times, the RNs advised the caller to just go to bed:

I recall one person who said - 'I am going to cut myself'... After talking it over and leading the conversation into other areas I finally told the person - 'You are not going to cut yourself. You are going to bed now!' (No 5)

The RNs had to sometimes use great effort to calm the caller to obtain needed information and to be able to give advice. They are on their way to you [the ambulance], but meanwhile I need you to calm down and tell me what has happened'. However, sometimes we don't succeed. They just keep on screaming (No 15).

\section{To not obtain reliable information}

Registered nurses described language barriers as a significant issue during their interviews. Immigrants, tourists and particularly people living in the northern part of Sweden close to the border of Finland were difficult to understand. In the camps for newly arrived immigrants, an interpreter was often needed, but the person often could not speak English well.

Many calls were from people who were somehow related to the person in need. Often, it was a close relative (e.g., parent, wife or husband) neighbour or friend. The callers usually did not have medical training. The nurses found it difficult to obtain correct and reliable information if they asked the following questions: 'What colour is the person's skin?', 'Are they having difficulty breathing?', and 'Does the pulse feel normal?' Not being able to see the patient with their own eyes was described as a significant obstacle to a proper assessment. Decisions about dispatching an ambulance often created feelings of uncertainty (e.g., if the symptoms were indistinct and vague). These diffuse ordinary cases can be something very serious (No 4).

The RNs stated that there were different response times depending on if an ambulance was sent to a rural part of the country compared to a large city, and this factor sometimes influenced their decision-making. Once I sent a stroke-patient with obvious stroke symptoms, a priority 1 patient, with a taxi. The ambulance was $80 \mathrm{~km}$ away, and we had two stroke patients in the same village (No 11). The RNs also discovered that people in rural areas had different expectations than people who lived in more densely populated areas. Some people were more prepared to transport themselves with their own cars and then meet an ambulance along the road.

\section{To give the caller instructions}

Instructing cardio-pulmonary resuscitation (CPR) via telephone was described as a substantial challenge for the RNs. They first had to make the decision to begin CPR, and then the RN had to give detailed instructions to the helper on the phone and encourage the helper to continue until the ambulance arrived. The $\mathrm{RN}$ encountered a dilemma if the chance for a successful result seemed to be extremely small, but the $\mathrm{RN}$ still needed to encourage the helper to continue CPR. Helpers who are alone with a seriously wounded patient must also be instructed and supported mentally while waiting for the ambulance, and the nurses found those situations very exhausting. They identified themselves with the caller and understood the helper's difficult situation.

\section{To get depressing calls}

Talking to people who just found their partner dead or parents whose children had just committed suicide was described as extremely depressing for the RNs. Additionally, calls from individuals who suffered from anxiety and loneliness were considered negative and depressing. The pressure from stressed callers who became real threats was also a negative experience. The nurses described that a method to cope with this type of caller was to inform them that the calls were recorded:

"Everything you and me say is recorded. If anything goes wrong and it shows that my triage is not correct ..." Then, they change their mind very quickly. (No 7)

\section{To be criticised}

The RNs also had negative experiences if they were criticised by ambulance crews for overprioritising patients and 
were accused for unnecessarily dispatching ambulances. Additionally, RNs described that conflicts with colleagues were also negative experiences (e.g., district-nurses) if they wanted an ambulance and the nurse at the EMD decided it was unnecessary. ... among the worst ones are your own colleagues who are not used to be questioned. "I am actually a nurse. I have already made a triage, so I don't need to discuss with anyone" (No 2). If the RNs were doubtful about the need of hospital transport, they expected that the arrival of the ambulance would lead to an accurate decision concerning the patient. In particular situations, a district nurse can make the assessment. The RNs at the EMD found it important to not send ambulances to all callers because of limited resources and because of the fear of long waiting times for new callers if all ambulances in the area were occupied.

In several of the interviews, a special case was mentioned. A 23-year-old man in Sweden died after calling for an ambulance three times. The cause of death was a spontaneous spleen rupture. This incident was highly publicised and debated in the media, and the $\mathrm{RN}$ who had refused to send an ambulance was prosecuted but acquitted. The nurses were aware of the risk of being reported if they made a wrong decision. Because this is all about not doing wrong. I don't want to lose my license (No 8).

\section{Discussion}

Our study provides important insights into registered nurses' experiences at an Emergency Medical Dispatch Centre. The findings related to the theme 'Having a profession with opportunities and obstacles' showed that the combination of knowledge, experience and intuition are essential factors for good decision-making. Because the decisions involved are comparable to additional forms of triage, studies investigating other telephone triage settings and ED nursing triage should be conducted. According to Wahlberg et al. (2003), RNs have advised patients on care and directed them to appropriate health care via telephone for decades. The most common duty has been advising in primary care (Edwards 1994, Purc-Stephenson \& Thrasher 2010, Huibers et al. 2012).

The RNs in the present study underlined the importance of their previous nursing experiences and the usefulness of their experiences from other healthcare areas. The participants were proud of being RNs. This finding is in accordance with Forslund et al. (2006) who found that when RNs began working at the EMDs in Sweden, the operators who already worked there considered the RNs to be proud of their profession. A meta-ethnographic review of sixteen studies showed that tele-nurses emphasised the importance of strong clinical knowledge (Purc-Stephenson \& Thrasher 2010).

The RNs in our study also expressed that intuition plays an important role in making difficult decisions. The concept of intuition is discussed in a review of various clinical decision-making models (Banning 2007). The author described the 'intuitive-humanist' model as different from the 'information-processing' model, and the narratives of the RNs in our study indicate that there are elements of both models in their decision-making. In describing their work at the EMD, the nurses believed that their experiences and knowledge as RNs increased the quality of their decisions. They stated that the Medical Index was important and that it should be followed but that in particular situations their decisions were determined by other methods.

Purc-Stephenson and Thrasher (2010) explained that there is little knowledge about whether 'highly-skilled' RNs, who provide advice in primary care, follow their decision-support systems. They found variations in the degree of autonomy and that some nurses resisted protocols by using their own clinical knowledge if they believed their index led to an inappropriate decision. A study from Norwegian EMDs, where the dispatching is normally performed by RNs with experience in emergency or intensive care, showed a relatively high overall use but with large individual variations in the use of the Index. The lowest use was reported by RNs who worked in ambulance services in addition to the EMD (Ellensen et al. 2014). Huibers et al. (2012) found that RNs in telephone-triage did not ask all recommended questions in their history taking, but this factor did not affect the appropriateness of their estimation of urgency. If the RNs in our study chose to rely on their own experience and knowledge instead of strictly following the Medical Index, they followed a strategy that is commonly used among experienced nurses.

The RNs in our study were mostly satisfied with their work at the EMD. They encountered many challenging situations, but they also had positive experiences when they could support and help people in need. The importance of advice and pre-arrival instructions during the waiting time for an ambulance was emphasised by an expert group at Utstein Consensus Symposium (Castrén et al. 2008). This group also stated that the dispatch process is complex and must be recognised as an essential part of the medical response.

The findings related to the second theme of 'Meeting serious and difficult situations' described the stressful and also depressing aspects of working at an EMD. The RNs in the present study described situations that were both complex and demanding. They were aware of the importance of 
their decisions, and therefore they strongly considered all of the information they received during the calls to make a correct and objective assessment of the caller's need. However, the RNs had to consider that if they misunderstood the situation and refused to send the ambulance to a person with a severe condition, they could be reported and potentially prosecuted.

The RNs in our study knew that the number of ambulances was limited and that the overuse of resources can lead to longer waiting times. Numerous studies have noted an overuse of ambulances and an over-prioritisation of ambulance dispatches as a problem in Western countries (Hjälte et al. 2007, Machen et al.2007, Khorram-Manesh et al. 2010, Gardett et al. 2013). In a study by Hjälte et al. (2007) only $10 \%$ of the dispatches that were given Priority 1 really warranted that level of priority. Khorram-Manesh et al. (2010) found that $30 \%$ of the ambulance transports were unnecessary. In the UK, approximately $50 \%$ of people who are transported to a hospital could have been cared for at the scene (Machen et al. 2007). The Swedish National Audit Office (2012) found an increasing hesitance from EMDs to refuse dispatching ambulances if a caller demanded it. Our findings showed that the RNs were very aware of this problem but they found their ability to avoid 'unnecessary' ambulance transports to be limited. The conflict to be both a carer and a gate-keeper encountered by tele-nurses in providing health care advice has been described by Holmström and Dall'Alba (2002).They found that the RNs they interviewed struggled with a conflict between the care they wanted to give and the reality they faced. In our study, the RNs described the same conflicts as burdening.

RNs who work on the 'front line' in the EDs at hospitals also encounter the risk of over-prioritising rapid assessment for particular patients, thereby causing long wait times for other patients. These RNs believed that they tended to make safe decisions, which led to difficult working situations in the ED (Elmqvist et al. 2012). Andersson et al. (2006) found that RNs with many years of experience in ED triage brought a sense of security to the team and that less experienced colleagues asked them for advice and support. Huibers et al. (2012) found that if tele-nurses were uncertain, they tried to make safe decisions, resulting in overestimating the urgency of the call. The RNs in our study were the first contact in emergency care, unlike RNs in hospital EDs, and their duty was to decide if an ambulance should be dispatched. This duty was a burden, and they described that the uncertainty and pressure they often felt most likely led to an overuse of ambulances.

In the present study, the participants found that not being able to see the patient with their own eyes was difficult, and they had to trust the caller's descriptions. Additional analysis of the telephone triage showed that this type of triage was complicated and that nurses in this work must rely on 'auditory cues' (Pettinari \& Jessopp 2001, Purc-Stephenson \& Thrasher 2010, Huibers et al. 2012). Huibers et al. (2012) reported that there are substantial variations in patients' abilities to describe their symptoms. Our findings illuminate the difficulties in obtaining reliable information. These difficulties depend on the caller's ability to describe symptoms, language skills, mental status and intoxication status. Pettinari and Jessopp (2001) concluded that the absence of visibility is a challenge, and it can influence the caller's ability to narrate and describe their physical conditions in various ways. Particular callers find it easier to discuss personal matters. They also found that RNs with more than six months of experience had developed their strategies for mastering these difficulties.

In a study from the early 1990s, the components of diagnostic reasoning used by experienced nurses during telephone triage were described. It was concluded that the triage was made by balancing the most probable outcome against the worst possible outcome (Edwards 1994). The expert group at the Utstein Consensus Symposium concluded that the dispatch process is complex and that both research and quality assurance processes are necessary (Castrén et al. 2008). We found that the RNs at EMDs were ethically and emotionally affected in making their decisions, and they also adopt risk-minimising actions to be cautious, although it may be contrary to their clinical judgment.

\section{Methodological discussion}

The number of interviews could be considered low, but all interviews were rich in content. However, there are no rules about sample size in qualitative research. Sample size depends on what we want to know, the purpose of the study, what will be useful, what will have credibility, and what can actually be done with the time and resources available (Morse 2000, Patton 2002, Polit \& Beck 2008). The results generated from qualitative inquiry have more to do with the information richness and the analytical capabilities of the researcher than with the sample size (Patton 2002).

To discuss trustworthiness, the following concepts will be used: credibility, dependability, transferability, conformability and authenticity (Polit $\&$ Beck 2008). The credibility of the content analysis of the interviews depends on the participants' willingness and ability to describe their experiences (cf. Patton 2002). All of the nurses who were interviewed in our study were or had been employed at the EMD because of their communication skills, amongst other 
qualities. They showed a great interest in describing the content of their work and their experiences. When asked about any specially challenging or difficult situations, all of the participants gave examples from their own experiences (cf. Flanagan 1954). The interpretation of the text was judged to be the most probable in comparison to other interpretations. There was an ongoing discussion between the authors regarding the data analysis method and the interpretation of the findings. We assume that this approach strengthened the credibility. The dependability of an interview study can be at risk if the data collection is conducted during a long period or if the interview questions are changed based on new insights the researcher gains (cf. Graneheim \& Lundman 2004). Data collection was performed during a period of only three months, and we therefore assumed this risk to be limited. The degree to which the findings are transferable to other areas is uncertain. However, the problems and difficulties encountered by the RNs in this study are comparable to all fields of decision-making and triage performed by nurses (cf. Down-Wamboldt 1992, Shenton 2004). Conformability was established by discussions between the authors and by references to studies with similar results. Authenticity was sought by keeping the analysis close to the interview texts and by giving examples from the analysis, as well as verbatim quotations (Polit \& Beck 2008).

\section{Limitations}

Employing nurses for triage at EMDs is relatively new in Sweden. Therefore, RNs' experiences in this study were limited to an average of 15 months. Admittedly this sample may be too homogeneous, but the risk was considered small because the participants received calls from various parts of Sweden. The findings may have also been different if the interviews were conducted with nurses with longer experience.

\section{Conclusion and relevance to clinical practice}

We found that ambulance dispatch is both challenging and difficult. The difficulties include conveying medical advice without seeing the patient, teaching cardio-pulmonary resuscitation via telephone and dealing with intoxicated and aggressive callers. Conflicts with colleagues and ambulance crews as well as the fear of making wrong decisions were found to be challenging. Gardett et al. (2013) found in a systematic literature review that there are significant gaps and limitations in the knowledge about emergency dispatch. They argued that dispatchers will benefit from participating in studies that validate their professional value. We conclude that triage at an EMD is a demanding but also stimulating duty for nurses. There are great benefits, including increased safety for patients and better use of medical resources, if experienced RNs perform triage. Improving internal support systems at the EMDs and striving for a blame-free culture are important factors for attracting and retaining employees.

\section{Acknowledgements}

The authors thank the RNs who participated in the interviews and Magnus Backman, Senior Manager in the Department of Care at SOS Alarm AB for his assistance with this project.

\section{Disclosure}

The authors have confirmed that all authors meet the ICMJE criteria for authorship credit (www.icmje.org/ethical_1author.html), as follows: (1) substantial contributions to conception and design of, or acquisition of data or analysis and interpretation of data, (2) drafting the article or revising it critically for important intellectual content and (3) final approval of the version to be published.

\section{Funding}

This study was supported by grants from Laerdal Foundation, Stavanger, Norway.

\section{Conflicts of interest}

No conflicts of interest have been declared by the authors.

\section{References}

Andersson A-K, Omberg $M$ \& Svedlund $M$ (2006) Triage in the emergency department - a qualitative study of the factors which nurses consider when making decisions. Nursing in Critical Care 11, 136-145.

Banning M (2007) A review of clinical decision making: models and current research. Journal of Clinical Nursing 17, 187-195.

Bucknall TK (2000) Critical care nuses'decision-making activities in the 
natural clinical setting. Journal of Clinical Nursing 9, 25-36.

Castrén M, Karlsten R, Lippert F, Christensen EF, Bovi E, Kvam AM, Robertson-Steel I, Overton J, Kraft T, Engerström L \& Garcia-Castrill Riego L (2008) Recommended guidelines for reporting on emergency medical dispatch when conducting research in emergency medicine: the Utstein style. Resuscitation 79, 193-197.

Chan JNH \& Chau J (2005) Patient satisfaction with triage nursing care in Hong Kong. Journal of Advanced Nursing 50, 498-507.

Down-Wamboldt B (1992) Content analysis: method, applications, and issues. Health Care for Women International 13, 313-321.

Edwards B (1994) Telephone triage: how experienced nurses reach decisions. Journal of Advanced Nursing 19, 717-724.

Ek B, Edström P, Toutin A \& Svedlund M (2013) Reliability of a Swedish prehospital dispatch system in prioritizing patients. International Emergency Nursing 21, 143-149.

Ellensen E, Hunskar S, Wisborg T \& Zackariassen E (2014) Variations in contact patterns and dispatch guideline adherence between Norwegian emergency medical communication centres - a cross-sectional study. Scandinavian Journal of Trauma, Resuscitation and Emergency Medicine, 22 (webb-publication), 1-10, doi:10.1186/ 1757-7241-22-2.

Elmqvist C, Fridlund B \& Ekeberg M (2012) Trapped between doing and being: first providers'experience of "front line" work. International Emergency Nursing 20, 113-119.

Ernesäter A, Winblad U, Engström M \& Holmström K (2012) Malpractice claims regarding calls to Swedish telephone advice nursing: what went wrong and why? Journal of Telemedicine and Telecare 18, 379-383.

Feldman MJ, Verbeek PR, Lyons DG, Chad SJ, Craig AM \& Schwartz B (2006) Comparison of the medical priority dispatch system to an out-of-hospital patient acuity score. Academic Emergency Medicine 13, 954-960.

Flanagan J (1954) The critical incidence technique. Psychological Bulletin 51, 327-358.
Forslund K, Kihlgren M \& Sørlie V (2006) Experiences of adding nurses to increase medical competence at an emergency medical dispatch centre. Accident and Emergency Nursing 14, 230-236.

Gardett I, Clawson J, Scott G, Tracey Barron T, Patterson B \& Olola C (2013) Past, present and future of emergency dispatch research: a systematic literature review. Annals of Emergency Dispatch \& Response 1, 29-42.

Graneheim UH \& Lundman B (2004) Qualitative content analysis in nursing research: concepts, procedures and measures to achieve trustworthiness. Nurse Education Today 24, 105-113.

Handysides G (1996) Triage in Emergency Practice. Mosby-Year Book Inc, St Louis, MO.

Hedberg B \& Sätterlund Larsson U (2003) Observations, confirmations and strategies - useful tools in decision-making process for nurses in practice. Journal of Clinical Practice 12, 215-222.

Hinchey P, Myers B, Zalkin J, Lewis R \& Garner D (2007) Low acuity EMS dispatch criteria can reliably identify patients without high-acuity illness or injury. Prehospital Emergency Care 11, 42-48.

Hjälte L, Suserud B, Herlitz J \& Karlberg I (2007) Why are people without medical needs transported by ambulance? A study of indications for pre-hospital care. European Journal of Emergency Medicine 14, 151-156.

Holmström I \& Dall'Alba G (2002) 'Carer and gatekeeper' - conflicting demands in nurses'experiences of telephone advisory services. Scandinavian Journal of Caring Sciences 16, 142-148.

Huibers L, Keizer E, Giesen P, Grol R \& Wensing M (2012) Nurse telephone triage: good quality associated with appropriate decisions. Family Practice 29, 547-552.

Khorram-Manesh A, Lennquist Montán K, Hedelin A, Kihlgren M \& Örtenwall PO (2010) Prehospital triage, discrepancy in priority-setting between emergency medical dispatch centre and ambulance crews. European Journal of Trauma and Emergency Surgery 37, 73-78.

Machen I, Dickinson A, Williams J, Widiatmoko D \& Kendall S (2007) Nurses and paramedics in partnership: perceptions of a new response to low- priority ambulance calls. Accident and Emergency Nursing 15, 185-192.

Morse JM (2000) Determining sample size. Qualitative Health Research 10, 3-5.

Muir N (2004) Clinical decision-making: theory and practice. Nursing Standard $19,47-54$.

Patton MQ (2002) Qualitative Research \& Evaluation Methods, 3rd edn. Sage, London.

Pettinari CJ \& Jessopp L (2001) "Your ears become your eyes": managing the absence of the visibility in NHS Direct. Journal of Advanced Nursing 36, 668675.

Polit DF \& Beck CT (2008) Nursing Research: Generating and Assessing Evidence for Nursing Practice, 8th edn. Lippincott Williams \& Wilkins, Philadelphia, PA.

Purc-Stephenson R \& Thrasher C (2010) Nurses' experiences with telephone triage and advice: a meta-ethnography. Journal of Advanced Nursing 66, 482494.

Shenton AK (2004) Strategies for ensuring trustworthiness in qualitative research projects. Education for Information $22,63-75$.

SOS Alarm AB (2013a) SOS Alarm AB. Available at: http://www.sosalarm.se/ 112/Om-112/Att-larma-112/English/ (accessed 05 February 2014).

SOS Alarm AB (2013b) SOS Alarm AB [swe.]. Available at: http://www.sosalarm.se/Vara-tjanster/Vard/Utalarmering-av-ambulans/ (accessed 05 February 2014).

Sporer K, Youngblood G \& Rodriguez R (2007) The ability of emergency medical dispatch codes of medical complaints to predict ALS prehospital interventions. Prehospital Emergency Care 11, 192-198.

Swedish Index for Medical Priority Dispatch (Svenskt index för akutmedicinsk larmmottagning) (2001) Åsmund S. Lærdal A/S, Stavanger. ISBN 8291823-19-7

Swedish National Audit Office (2012). Riksrevisionen 2012:20 [swe.]. Statens insatser inom ambulansverksamheten. ISBN 978-91-7086-298-4

Wahlberg AC, Cedersund E \& Wredling R (2003) Telephone nurses' experience of problems with telephone advice in Sweden. Journal of Clinical Nursing 12, $37-45$. 
The Journal of Clinical Nursing (JCN) is an international, peer reviewed journal that aims to promote a high standard of clinically related scholarship which supports the practice and discipline of nursing.

For further information and full author guidelines, please visit JCN on the Wiley Online Library website: http:// wileyonlinelibrary.com/journal/jocn

\section{Reasons to submit your paper to JCN:}

High-impact forum: one of the world's most cited nursing journals, with an impact factor of 1.316 - ranked 21/101 (Nursing (Social Science)) and 25/103 Nursing (Science) in the 2012 Journal Citation Reports ${ }^{\circledR}$ (Thomson Reuters, 2012).

One of the most read nursing journals in the world: over 1.9 million full text accesses in 2011 and accessible in over 8000 libraries worldwide (including over 3500 in developing countries with free or low cost access).

Early View: fully citable online publication ahead of inclusion in an issue.

Fast and easy online submission: online submission at http://mc.manuscriptcentral.com/jcnur.

Positive publishing experience: rapid double-blind peer review with constructive feedback.

Online Open: the option to make your article freely and openly accessible to non-subscribers upon publication in Wiley Online Library, as well as the option to deposit the article in your preferred archive. 